\title{
Assignments of Optically Active Absorption Bands in the Tris- (ethylenediamine)chromum(III) Chromophore Obtained from Single Crystal Circular Dichroism Spectra
}

\author{
HANS PETER JENSEN
}

Chemistry Department A, Building 207, Technical University of Denmark. DK-2800 Lyngby. Denmark

Crystal circular dichroism spectra of $(-)_{D}-\left[\mathrm{Cr}(\mathrm{en})_{3}\right]$ $\mathrm{Cl}_{3} \cdot 2 \mathrm{H}_{2} \mathrm{O}$ and $\left[(+)_{\mathrm{D}}-\mathrm{Cr}(\mathrm{en})_{3}-(+)_{\mathrm{D}}-\mathrm{Rh}(\mathrm{en})_{3}\right] \mathrm{Cl}_{6}$ - $^{-}$ $6 \mathrm{H}_{2} \mathrm{O}$ in the ligand field region are analyzed in order to provide information about the rotatory strengths of the two trigonal components $\left({ }^{4} E\right.$ and ${ }^{4} A_{2}$ ) under the ${ }^{4} T_{1 g} \leftarrow{ }^{4} A_{2 g}$ octahedral parent transition. The trigonal splitting is found to be $150 \mathrm{~cm}^{-1}$ with the transition to the $E$ excited level at the highest energy. The rotatory strengths of the $(+)_{D^{-}}$ $\left[\mathrm{Cr}(\mathrm{en})_{3}\right]^{3+}$ chromophore are found to be $3.2 \times$ $10^{-40}$ and $-1.6 \times 10^{-40}$ (cgs units) for the transition to the $E$ and the $A$ excited level. respectively.

Circular dichroism (CD) spectra of trigonal complexes of cobalt(III) and chromium(III) have attracted much attention over the years, and different explanations for the relatively small rotatory strength under the spin-allowed $T \leftarrow A$ octahedral parent transitions have been proposed. ${ }^{1-6}$ Various experiments ${ }^{7-11}$ and calculations, ${ }^{12-14}$ however. provide good evidence that the visible solution $\mathrm{CD}$ spectra of $\left[\mathrm{Co}(1,2 \text {-diamine })_{3}\right]^{3+}$ and $[\mathrm{Cr}(1,2$-diamine) $\left.{ }_{3}\right]^{3+}$ chromophores in general can be regarded as due to residual wing absorptions, originating from extensive cancellation of the rotatory strengths of the two trigonal components, because of a small trigonal splitting. ${ }^{15}$

This assignment was verified experimentally for the $\left[\mathrm{Co}(\mathrm{en})_{3}\right]^{3+}$ chromophore in single crystals through phase modulation spectroscopy (PMS). which technique makes it possible to overcome the prohibitive complications of coexisting linear and circular anisotropies. ${ }^{16}$

As far as the corresponding chromium(III) complex is concerned. there are indications that the trigonal splitting $(\delta)$ of the $T \leftarrow A$ parent transition is of the same order of magnitude as in $\left[\mathrm{Co}(\mathrm{en})_{3}\right]^{3+}$ $\left(\sim 100 \mathrm{~cm}^{-1}\right)$. However, the transition to the $A$ excited level is expected at a lower energy than the transition to the $E$ level, ${ }^{15}$ while the opposite is true at least for $\left[\mathrm{Co}(\mathrm{en})_{3-x}(\mathrm{tn})_{x}\right]^{3+}$ chromophores. ${ }^{16,17}$

It was found, when single crystals of $(-)_{D^{-}}$ $\left[\mathrm{Cr}(\mathrm{en})_{3}\right] \mathrm{Cl}_{3} \cdot 2 \mathrm{H}_{2} \mathrm{O}$ were investigated by PMS, that indeed the transition to the $E$ excited level occurs at higher energy than the transition to the $A$ excited level. ${ }^{18}$ However. due to the crystal structure of the compound, ${ }^{19}$ exhibiting two crystallographically independent cations in the monoclinic unit cell (Fig. 1), transitions of specific polarisation directions with respect to the crystallographic axes are to a major extent averaged when the total structure is considered (cf. Tables 1 and 3 of Ref. 18). This means, when PMS is performed on $(-)_{D^{-}}$ $\left[\mathrm{Cr}(\mathrm{en})_{3}\right] \mathrm{Cl}_{3} \cdot 2 \mathrm{H}_{2} \mathrm{O}$ with the probing light beam propagated along the crystallographic $\mathbf{b}$ axis in order to fulfil the restrictions of the method, ${ }^{18}$ that we obtain spectra displaying $71 \%$ of the rotatory strength connected with transition to the $E$ excited level and $58 \%$ of the rotatory strength connected with transition to the $A$ excited level (cf. Table 3 of Ref. 18). Thus we cannot in the case of $(-)_{\mathrm{D}}-\left[\mathrm{Cr}(\mathrm{en})_{3}\right] \mathrm{Cl}_{3} \cdot 2 \mathrm{H}_{2} \mathrm{O}$ expect to obtain solid state CD spectra very much different from those obtained in solution. ${ }^{20}$ If, however, another salt of the $\left[\mathrm{Cr}(\mathrm{en})_{3}\right]^{3+}$ chromophore were available for PMS, the two sets of data could be combined to give more precise the positions and the intensities of the unperturbed trigonal $C D$ bands. Such a determination has been carried out in this paper by using $\left[(+)_{D}-\mathrm{Cr}(\mathrm{en})_{3}-(+)_{\mathrm{D}}-\mathrm{Rh}(\mathrm{en})_{3}\right] \mathrm{Cl}_{6} \cdot 6 \mathrm{H}_{2} \mathrm{O}$ 


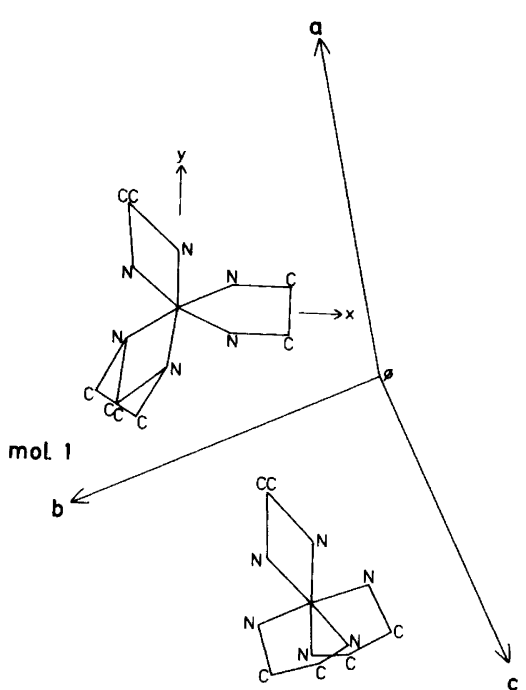

mol. 2

Fig. 1. Orientation of the two independent molecules in the crystallographic unit cell of $(-)_{D^{-}}\left[\mathrm{Cr}\right.$ en $\left.{ }_{3}\right]-$ $\mathrm{Cl}_{3} .2 \mathrm{H}_{2} \mathrm{O}$.

which salt crystallizes in the trigonal space group P321. ${ }^{21}$

\section{EXPERIMENTAL}

Crystals of the active racemate $\left[(+)_{\mathrm{D}}-\mathrm{Cr}(\mathrm{en})_{3^{-}}\right.$ $\left.(+)_{D}-\mathrm{Rh}(\mathrm{en})_{3}\right] \mathrm{Cl}_{6} \cdot 6 \mathrm{H}_{2} \mathrm{O}$ were obtained from Dr. Whuler at Université Pierre et Marie Curie in Paris. The crystals were elongated plates with (010) dominating. The experimental procedure as far as PMS and evaluation of the obtained spectra are concerned was the same as described earlier. ${ }^{18,22}$ The following abbreviations are used throughout this paper: en $=1,2$-ethanediamine, $\mathrm{pn}=1.2$-propanediamine, $t \mathrm{tn}=1,3$-propanediamine.

\section{RESULTS}

From an earlier investigation of the solid state CD of $(-)_{D}-\left[\mathrm{Cr}(\mathrm{en})_{3}\right] \mathrm{Cl}_{3} \cdot 2 \mathrm{H}_{2} \mathrm{O}$ we know the envelope of the sum of $71 \%$ rotatory strength of $E$ symmetry and $58 \%$ rotatory strength of $A$ symmetry. This sum multiplied with $1 / 0.71$ is given as $(E+0.8 A)$ for the $(+)_{\mathrm{D}}-\left[\mathrm{Cr}(\mathrm{en})_{3}\right] \mathrm{Cl}_{3} \cdot 2 \mathrm{H}_{2} \mathrm{O}$ enantiomer in Fig. 2 .

The crystal $\mathrm{CD}$ spectrum of the active racemate measured with the probing light beam propagated

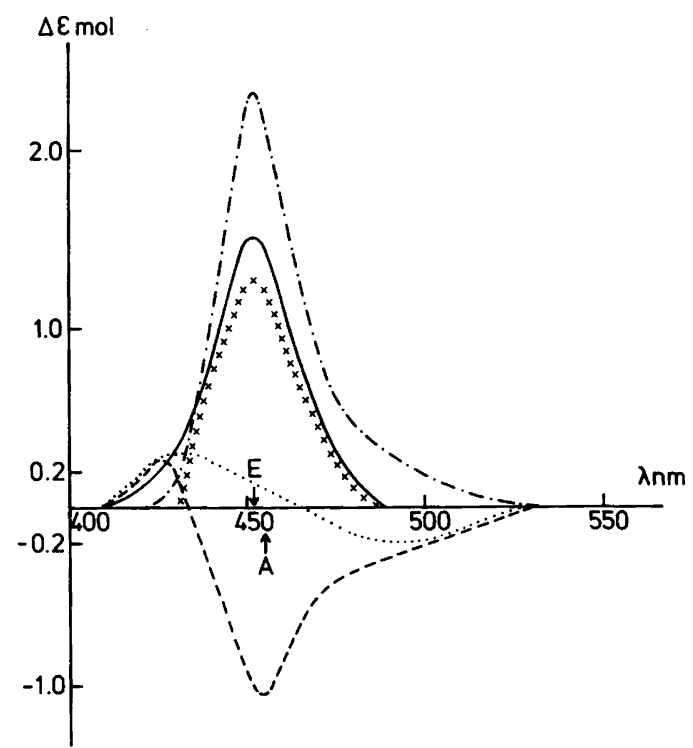

Fig. 2. Component $\mathrm{CD}$ spectra of the $(+)_{\mathrm{D}^{-}}$ $\left[\mathrm{Cr}(\mathrm{en})_{3}\right]^{3+}$ chromophore in the ${ }^{4} T_{1 g} \leftarrow{ }^{4} A_{2 g}$ octahedral parent transition region. $-E+0.8 A$; $\ldots, A+0.5 E ;-\cdot-, E ;---, A ; \times, E+A$.

perpendicular to the crystallographic $\mathbf{c}$ axis is also given in Fig. 2. This spectrum represents a sum of rotatory strengths which may be symbolized as $(A+0.5 E){ }^{16}$

Now it is of course possible to determine both the $E$ and the $A$ contribution by simple arithmetics. This is done in Table 1 and the result is shown in Fig. 2, together with the original spectra and the average $(A+E)$, i.e. the random $\mathrm{CD}$ spectrum. The latter is given for comparison with the actual solution $\mathrm{CD}$ spectrum of the $(+)_{\mathrm{D}^{-}}-\left[\mathrm{Cr}(\mathrm{en})_{3}\right]^{3+}$ chromophore. ${ }^{20}$ The pure $A$ component obtained from the two experimental data sets has a rather unusual shape, indicating some uncertainty in the determination. If this uncertainty, however, originates in the very different band widths of the two experimental $C D$ spectra, the inaccuracy should be biggest at the edges of the two component spectra.

\section{DISCUSSION}

Considering Fig. 2 and Table 1, it is quite obvious that the solution (random) $\mathrm{CD}$ spectrum in the ligand field range of the $\left[\mathrm{Cr}(\mathrm{en})_{3}\right]^{3+}$ chromophore may be regarded as residual wing absorption 
Table 1. Determination of the trigonal components under the ${ }^{4} T_{1 g} \leftarrow{ }^{4} A_{2 g}$ octahedral parent transition in the $(+)_{D}-\left[\mathrm{Cr}(\mathrm{en})_{3}\right]^{3+}$ chromophore.

\begin{tabular}{llllll}
\hline $\mathrm{nm}$ & $E+0.8 A$ & $A+0.5 E$ & \multicolumn{1}{l}{$\boldsymbol{A}$} & \multicolumn{1}{l}{ A } & $E+A$ \\
\hline 520 & 0 & -0.06 & 0.08 & -0.1 & -0.02 \\
510 & 0 & -0.14 & 0.18 & -0.23 & -0.05 \\
500 & 0 & -0.19 & 0.25 & -0.31 & -0.06 \\
490 & 0 & -0.20 & 0.27 & -0.33 & -0.06 \\
485 & 0.09 & -0.17 & 0.37 & -0.35 & 0.02 \\
480 & 0.16 & -0.15 & 0.46 & -0.38 & 0.08 \\
475 & 0.29 & -0.10 & 0.61 & -0.40 & 0.21 \\
470 & 0.55 & -0.02 & 0.94 & -0.49 & 0.45 \\
465 & 0.83 & 0 & 1.37 & -0.68 & 0.69 \\
460 & 1.10 & 0.04 & 1.78 & -0.85 & 0.93 \\
455 & 1.46 & 0.10 & 2.30 & -1.05 & 1.25 \\
452 & 1.50 & 0.13 & 2.32 & -1.03 & 1.29 \\
450 & 1.41 & 0.17 & 2.13 & -0.90 & 1.23 \\
445 & 1.20 & 0.22 & 1.71 & -0.63 & 1.08 \\
440 & 0.79 & 0.26 & 0.97 & -0.22 & 0.75 \\
435 & 0.55 & 0.30 & 0.52 & 0.04 & 0.56 \\
430 & 0.31 & 0.28 & 0.14 & 0.21 & 0.33 \\
425 & 0.17 & 0.26 & -0.05 & 0.28 & 0.23 \\
420 & 0.11 & 0.18 & -0.06 & 0.21 & 0.15 \\
415 & 0.07 & 0.12 & -0.03 & 0.13 & 0.10 \\
410 & 0 & 0 & 0 & 0 & 0 \\
\hline
\end{tabular}

arising from extensive cancellation of the rotatory strengths of transitions to the trigonal components of the ${ }^{4} T_{1 g} \leftarrow{ }^{4} A_{2 g}$ octahedral parent transition. Secondly, it is possible to estimate the trigonal splitting to $\sim 150 \mathrm{~cm}^{-1}$ with the transition to the $A$ excited level at a lower energy than the transition to the $E$ excited level. It is also noteworthy that the rotatory strengths of the two isolated trigonal transitions have the following values: $R(E)=3.2 \times$ $10^{-40}$ (cgs units) and $R(A)=-1.6 \times 10^{-40}$ (cgs units). These numbers have been evaluated according to the formula: ${ }^{23}$

$R=2.45 \times 10^{-39}\left(\varepsilon_{1}-\varepsilon_{\mathrm{d}}\right)_{\max } \frac{\Delta v_{\frac{1}{2}}}{v}$

The experimental values for $R(E)$ and $R(A)$ given above are in agreement with those calculated by Evans et al. ${ }^{13}$ in the sense that $R(E)$ and $R(A)$ of the $\left[\mathrm{Cr}(\mathrm{en})_{3}\right]^{3+}$ chromophore are definitely smaller than the corresponding values for the $\left[\mathrm{Co}(\mathrm{en})_{3}\right]^{3+}$ chromophore. However, the experimental values of the present paper are somewhat smaller than the calculations $\left(R(E)=13.5 \times 10^{-40}(\mathrm{cgs})\right.$ and $R(A)=$ $\left.-12.4 \times 10^{-40}(\mathrm{cgs})\right){ }^{13}$ It was also in the case of the $\left[\mathrm{Co}(\mathrm{en})_{3}\right]^{3+}$ chromophore found through PMS that the experimental rotatory strengths for the two trigonal components ${ }^{16}$ were somewhat smaller than the calculated values, ${ }^{13}$ which could indicate that the method of Evans et al. is prone to overestimate rotatory strengths.

Another reason for the discrepancy could be that $(+)_{\mathrm{D}}-\left[\left(\mathrm{Cr}(\mathrm{en})_{3}\right] \mathrm{Cl}_{3} \cdot 2 \mathrm{H}_{2} \mathrm{O}\right.$ in the crystal structure is not in a pure tris lel conformation (Fig. 1) as in the active racemate. However, from calculations ${ }^{13}$ as well as from experiments ${ }^{9}$ we know that conformational contributions to the rotatory strength are an order of magnitude less than configurational contributions at least in the case of $\left[\mathrm{Co}(\mathrm{en})_{3}\right]^{3+}$ and $\left[\mathrm{Co}(\mathrm{pn})_{3}\right]^{3+}$ chromophores.

Acknowledgements. My sincere thanks are due to Professor J. A. Schellman, Institute of Molecular Biology, University of Oregon, for the opportunity to visit his laboratory and use his equipment. Also, I would like to thank Dr. A. Whuler, Université Pierre et Marie Curie, Paris, for specimens of the active racemate discussed in this paper. Grants from Danish Natural Science Research Council and NATO are highly appreciated.

\section{REFERENCES}

1. McCaffery, A. J. and Mason, S. F. Mol. Phys. 6 (1963) 359.

2. McCaffery, A. J., Mason, S. F. and Normann, B. J. Chem. Commun. (1966) 661.

3. Schäffer, C. E. Proc. R. Soc. London A 297 (1967) 96.

4. Kuroda, R. and Saito, Y. Bull. Chem. Soc. Jpn. 49 (1976) 433.

5. Woldbye, F. Rec. Chem. Prog. 24 (1963) 197.

6. Dingle, R. and Ballhausen, C. J. K. Dan. Vidensk. Selsk., Mat.-Fys. Medd. 35 (1967) No. 12.

7. Piper, T. S. and Karipides, A. G. J. Am. Chem. Soc. 86 (1964) 5039.

8. Sudmeier, J. L., Blackmer, G. L., Bradley, C. H. and Anet, F. A. L. J. Am. Chem. Soc. 94 (1972) 757.

9. Harnung, S. E., Kallesøe, S., Sargeson, A. M. and Schäffer, C. E. Acta Chem. Scand. A 28 (1974) 385.

10. Toftlund, H. and Petersen, E. Acta Chem. Scand. 26 (1972) 4019.

11. Judkins, R. R. and Royer, D. J. Inorg. Chem. 13 (1974) 945.

12. Strickland, R. W. and Richardson, F. S. Inorg. Chem. 12 (1973) 1025.

13. Evans, R. S., Schreiner, A. F. and Hauser, P. J. Inorg. Chem. 13 (1974) 2185. 
14. Mason, S. F. and Seal, S. H. Mol. Phys. 31 (1976) 755.

15. Bürer, T. Helv. Chim. Acta 46 (1963) 2388.

16. Jensen, H. P. and Galsbøl, F. Inorg. Chem. 16 (1977) 1294.

17. Jensen, H. P. Acta Chem. Scand. A 33 (1979) 749.

18. Jensen, H. P. Appl. Spectrosc. 34 (1980) 360.

19. Whuler, A., Brouty, C., Spinat, P. and Herpin, P. Acta Crystallogr. B 33 (1977) 2877.

20. Rancke-Madsen, E. and Woldbye. F. Acta Chem. Scand. 26 (1972) 3405.

21. Whuler, A., Brouty, C., Spinat, P. and Herpin, P. Acta Crystallogr. B 32 (1976) 2542.

22. Jensen, H. P., Schellman, J. A. and Troxell, T. Appl. Spectrosc. 32 (1978) 192.

23. Woldbye. F. Studier over Optisk Aktivitet, Polyteknisk Forlag, Copenhagen 1969.

Received January 29, 1980. 